\title{
Educación y enseñanza en tiempos de COVID-19
}

\author{
Silvia Iveth Martínez Álvarez
}

\author{
"De todo quedaron tres cosas: \\ la certeza de que estaba siempre comenzando, \\ la certeza de que había que seguir \\ y la certeza de que sería interrumpido antes de terminar.
}

Hacer de la interrupción un camino nuevo, hacer de la caída, un paso de danza, del miedo, una escalera, del sueño, un puente, de la búsqueda..., un encuentro"

Fernando Pessoa

$\mathrm{P}$ ara dimensionar el impacto de la crisis sanitaria provocada por la pandemia de coviD-19 sobre nuestra civilización a nivel global, podemos explorar los cambios en nuestro lenguaje, que finalmente es reflejo y construcción de nuestra vida cotidiana y forma de entender, estar y relacionarnos con el mundo. Así pues, basta mencionar que, durante los últimos meses, el término confinamiento fue elegido por el Oxford English Dictionary como una de las palabras que marcaron el lenguaje en el 2020, mientras que la Real Academia de la Lengua Española incorporó covid, coronavirus y desconfinamiento como parte de las palabras "oficialmente" reconocidas en el idioma castellano.

Quizá el cambio más radical y visible que trajo consigo la pandemia se encuentra en el ámbito de las interacciones sociales. El confinamiento obligó a suspender la mayoría de las actividades que implican la interacción cara a cara y la proximidad física. En nuestro país, las actividades en los recintos escolares fueron las primeras en detenerse. 
Ante la vorágine de incertidumbres que trajo consigo el confinamiento por la pandemia de CoviD-19, surgió una certeza: la gran mayoría de los docentes lograron la proeza de dar continuidad a sus tareas de enseñanza. Para ello, recurrieron a los recursos y herramientas a su alcance, adptándolas a sus estrategias de enseñanza y a las necesidades de sus estudiantes. Todo sobre la marcha y en forma emergente.

Es por eso que, para comprender los efectos de la pandemia sobre el quehacer docente, pedagógico y de aprendizaje, el equipo editorial de la Revista Digital Universitaria lanzó una convocatoria dirigida docentes y estudiantes de todos los niveles educativos para compartir testimonios y reflexiones que dieran cuenta de cómo han vivido este proceso.

Así pues, en cada uno de los 23 testimonios (19 textos y 4 videos) que conforman este número especial, podremos encontrar respuestas a algunas de las interrogantes más frecuentes respecto a nuestro papel ante la pandemia por coviD-19, como la disertación sobre el porqué los seres humanos actuamos como lo hacemos ante las crisis, en el texto titulado "El animal humano y su comportamiento en emergencias", así como reflexiones sobre las dificultades de la enseñanza y contención ante la distancia física en "Cuando la vocación no te permite la sana distancia".

Múltiples interrogantes relacionadas con lo pedagógico y didáctico son abordadas en testimonios como el de "La educación ante la pandemia: claves iniciales para superar brechas y poner manos a la obra", y "7 preguntas reflexivas para la mejora de la enseñanza en la formación técnico-profesional", que dan cuenta de la sistematización de experiencias de innovación educativa, y proporcionan indicios que desatan reflexiones para mejorar la enseñanza, respectivamente.

Los relatos incluyen historias de colaboración entre generaciones, en escenarios en donde confluye lo profesional, lo personal y el vínculo con la tecnología como en "El aula virtual y la olla expréss", así como ejemplos de flexibilización de las actividades planificadas y la construcción de alternativas para aprovechar al máximo las posibilidades que brinda la tecnología, como en "La voz de un profesor de asignatura de la Facultad de Medicina", "La enseñanza universitaria en odontología durante la pandemia" y "La Cátedra Digital: un modelo hiflex para la contingencia sanitaria".

Además, en cada uno de los testimonios está presente la dimensión emocional, con narraciones que muestran preocupación, disposición y compromiso de parte de los y las docentes para permanecer cercanos a sus estudiantes, abriendo espacios para el diálogo afectivo porque reconocen que "Ningún lugar está lejos cuando se ama" y que siempre hay sorpresas cuando se enseña a través de una pantalla. 
También encontraremos reflexiones profundas y honestas sobre experiencias con las que nos podremos identificar, nos conmoverán y nos harán sentir orgullo por la nobleza y la fortaleza con la que nuestros colegas han colocado su vocación de servicio por encima de las enormes dificultades personales que pudieran estar enfrentando mientras van "Sobreviviendo a la covid-19" y reinventando la docencia, para asegurar que "No hay crisis inútil".

Sirva pues este número especial de la Revista Digital Universitaria para abonar al diálogo y a la reflexión necesarias en tiempos donde la incertidumbre nos convoca a renovar prácticas, escenarios y creencias, pues como dice el poema de Fernando Pessoa, nos queda la certeza de que podemos "hacer de la interrupción un camino nuevo".

\section{Silvia Iveth Martínez Álvarez}

silvia martinez@cuaieed.unam.mx orcid.org/0000-0001-9359-794X

Psicóloga, egresada de la fes Zaragoza, Universidad Nacional Autónoma de México (UNAM), maestra y doctora en Ciencias, con la especialidad de Investigaciones Educativas por el cINVESTAV. Especialista en temas de género e interacción en contextos escolares, construcción social del aprendizaje, trayectorias escolares y construcción de identidades. Ha publicado artículos en revistas nacionales e internacionales, así como capítulos de libros y ponencias en eventos académicos especializados. Se ha desempeñado como docente a nivel medio superior y posgrado, y como consultora especializada en proyectos de investigación y desarrollo educativo, en diferentes instituciones. Actualmente se desempeña como Jefa del Departamento de Investigación en Educación en la Coordinación de Universidad Abierta, Innovación Educativa y Educación a Distancia (CUAIEED) de la UNAM.

\section{Cómo CITAR ESTE ARTículo}

* Martínez Álvarez, Silvia Iveth. (2021, enero-febrero). Educación y enseñanza en tiempos de covid-19. Revista Digital Universitaria (RDU), 22(1). Dol: http://doi. org/10.22201/cuaieed.16076079e.2021.22.1.0 
"Educación y enseñanza en tiempos de COVID-19"

Silvia Iveth Martínez Álvarez

Vol. 22, Núm. 1, enero-febrero 2021

Revista Digital Universitaria 